\title{
Measurement of Apparent Thermal Conductivity of JSC-1A Under Ambient Pressure
}

\author{
Zeng-Guang Yuan ${ }^{1}$ \\ National Center for Space Exploration Research, Cleveland, Ohio 44135 \\ and \\ Julie E. Kleinhenz ${ }^{2}$ \\ NASA Glenn Research Center, Cleveland, Ohio 44135
}

\begin{abstract}
The apparent thermal conductivity of JSC-1A lunar regolith simulant was measured experimentally using a cylindrical apparatus. Eleven thermocouples were embedded in the simulant bed to obtain the steady state temperature distribution at various radial, axial, and azimuthal locations. The high aspect ratio of a cylindrical geometry was proven to provide a one-dimensional, axisymmetric temperature field. A test series was performed at atmospheric pressure with varying heat fluxes. The radial temperature distribution in each test fit a logarithmic function, indicating a constant thermal conductivity throughout the soil bed. However, thermal conductivity was not constant between tests at different heat fluxes. This variation is attributed to stresses created by thermal expansion of the simulant particles against the rigid chamber wall. Under stress-free conditions $\left(20^{\circ} \mathrm{C}\right)$, the data suggest a temperature independent apparent conductivity of $0.1961 \pm 0.0070 \mathrm{~W} / \mathrm{m} /{ }^{\circ} \mathrm{C}$.
\end{abstract}

\section{Nomenclature}

$A$

$=$ first coefficient in the temperature modeling equation, ${ }^{\circ} \mathrm{C}$

$=$ second coefficient in the temperature modeling equation, ${ }^{\circ} \mathrm{C}$

$=$ coverage factor of expanded uncertainty, dimensionless

$=$ apparent thermal conductivity, $\mathrm{W} / \mathrm{m} /{ }^{\circ} \mathrm{C}$

$=$ thermal conductivity of fluid phase, $\mathrm{W} / \mathrm{m} /{ }^{\circ} \mathrm{C}$

$=$ thermal conductivity of solid phase, $\mathrm{W} / \mathrm{m} /{ }^{\circ} \mathrm{C}$

$=$ heat flux, $\mathrm{W} / \mathrm{m}^{2}$

$=$ total electric power to the heater, $\mathrm{W}$

$=$ coefficient of determination of a model function resulting from a lease-squares analysis

$=$ distance in radial direction, $\mathrm{m}$

$=$ temperature, ${ }^{\circ} \mathrm{C}$

$=$ average temperature of the sand bed, ${ }^{\circ} \mathrm{C}$

$=$ room temperature, ${ }^{\circ} \mathrm{C}$

$=$ expanded uncertainty, same dimension as the parameter

$=$ combined standard uncertainty of parameter $\mathrm{x}$, same dimension as parameter $\mathrm{x}$

$=$ bulk volume of the sand bed, $\mathrm{m}^{3}$

$=$ thermal expansion coefficient, ${ }^{\circ} \mathrm{C}^{-1}$

$=$ normalized temperature deviation of a non-baseline thermocouple, dimensionless

\section{Introduction}

key component of In Situ Resource Utilization on the Moon or Mars involves extraction of resources from the ground material (regolith). These extraction processes target bound water and oxygen, which can be released

\footnotetext{
${ }^{1}$ Staff Scientist, 21000 Brookpark Road, Cleveland, OH 44135, MS 110-3, AIAA Member.

${ }^{2}$ Research Engineer, Propulsion and Propellants Branch, MS 301-3, 21000 Brookpark Road, Cleveland, OH 44135, Senior Member.
} 
through endothermic reactions. For example, hydrogen reduction can be used to release oxygen from iron-oxides in lunar regolith. This requires a process temperature around $1000^{\circ} \mathrm{C}$, but experimentally measured data of JSC-1A thermal properties at this temperature range have not been reported. The knowledge of material properties is critical to efficient system design and effects the yield and time scale of reaction process.

When dealing with granular materials, a local thermal equilibrium is often assumed if there are no rapid temperature changes either in time or in space. Thus, for these cases, the heat transfer problem can be formulated based on a control volume which is much larger than the size of individual solid particles and the representative pore size. The granular material can be conceptually considered as a single phase composite material with a unified temperature field for both solid phase and fluid phase. The thermal properties of this composite material depend on the properties of both the solid and the fluid phases and their distribution. In addition, they are also affected by the motion status of the solid and the fluid. This is different from the properties of a single phase material which are normally intrinsic to the material. In other words, the properties of the composite material are situation-dependent, and their application should be limited to similar situations.

In this study, there is no bulk flow of the interstitial gas and the temperature field is in steady state. The granular medium, JSC-1 A regolith simulant, is in the presence of room air at atmospheric pressure and thus will be treated as a single composite material. The apparent thermal conductivity is defined as follows.

$$
\vec{q}=-k_{a} \nabla T
$$

where $k_{a}$ is the apparent thermal conductivity of the simulant, $T$ the bulk temperature of both solid phase and gas phase, and $\vec{q}$ the combined heat flux from both solid and gas phases. Note that although Eq. (1) has the same form as Fourier's law, it is fundamentally different. The thermal conductivity defined by Fourier's law is an intrinsic property of the material, whereas $k_{a}$, is not an intrinsic property of the simulant.

The apparatus developed in this investigation allows us to measure temperatures in multiple locations within the sand bed, contrary to previous conductivity measurements which only measured temperatures at the boundary points of the tested material. ${ }^{1-4}$ Additionally, the apparent thermal conductivity was measured at temperatures higher than what has been documented. An early version of this apparatus was used in a previous study which was mainly intended to test the methodology and functionality of the system. ${ }^{5}$ The limited data set used in this preliminary study suggested a temperature dependency of the apparent thermal conductivity. During recent modifications, instrument errors were uncovered which could account for this suggested dependency. After extensive modification, this new version of the apparatus can now be operated at higher temperatures and pressures lower than ambient. A larger test series was performed using an improved data reduction scheme. In the following, the new features of the apparatus and experimental results of the apparent thermal conductivity of JSC-1A will be discussed. Future tests are planned to explore effects of interstitial gas type and pressure as well as other simulant types.

\section{Experimental Setup and Test Procedures}

Figure 1 illustrates the overall arrangement of the experimental setup used for this investigation. The JSC-1A simulant under test is loaded into a cylindrical test cell where it is heated and temperature data are measured. The test cell and its peripheral devices will be described below in detail.

\section{A. The Test Cell}

The test cell was designed and fabricated at NASA Glenn Research Center. The primary design goal was to establish a one-dimensional, axisymmetric thermal field in the tested material. The ASTM standard recommends a one-dimensional Cartesian geometry, but this requires thermal insulation on the side walls in the lateral direction of the heat flow. When testing materials with low thermal conductivities, side wall insulation is difficult to implement, so that it often becomes the source of experimental errors. Previous investigations have shown that the apparent thermal conductivity of JSC-1A is very low, in the order of $0.2 \mathrm{~W} / \mathrm{m} /{ }^{\circ} \mathrm{C} \cdot{ }^{1-4}$ Thus, the method recommended by ASTM-C 518-04 does not seem to be practical in this investigation. The lateral heat loss problem of the Cartesian system is still present in this cylindrical geometry as heat loss through the top and bottom surfaces of the cylinder, referred to as end effects. The end-effects can be mitigated by employing a large aspect ratio of the cylinder design. 
A large aspect ratio was employed here and was proven to be effective based on measured temperatures.

Figure 2 shows two annotated photos of the test cell with an overall view on the left and the detailed internal structure on the right. Figure 3 is a schematic showing the locations of thermocouple junctions and the internal wiring.

The bottom portion of the test cell is a hollow cylindrical base with a threaded gas port and an electrical feed-through on its side wall. The electrical feed-through connects ten thermocouples to the data logging device. A porous aluminum plate covers the top surface to distribute gas flow into the soil bed. The quartz tube, which contains the soil, slides over the cylindrical base and an oring seal, which isolates the gas inside the test cell from the ambient air.

The middle portion of the test cell is the test section. A quartz tube confines the simulant particles in the test section. It has an inner and outer diameter of $51.87 \mathrm{~mm}$ and $58.17 \mathrm{~mm}$, respectively, and a length of $300 \mathrm{~mm}$. Three supporting rods and an upper plate form a frame accommodating ten Type K thermocouple (TC) wires and the electrical heater. The custom-built thermocouples were made

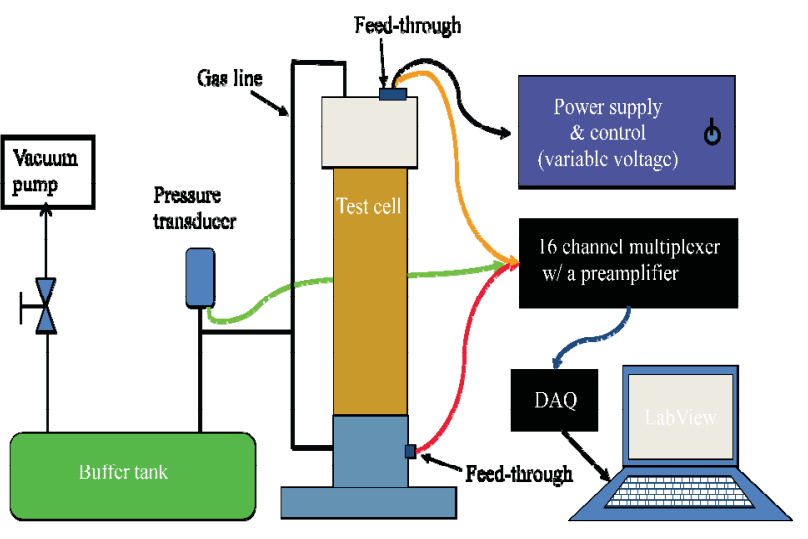

Figure 1. Experimental setup. The cylindrical test cell, is where JSC-1A regolith simulant is loaded and heated. Temperature data are recorded by a computer. of $0.2 \mathrm{~mm}$ diameter chromel and alumel wires. To form a TC junction, the two wires were placed end to end along a straight line and welded together with a precision laser beam. The TC junction has nearly the same diameter as the wires, instead of an enlarged bead of a traditional TC. The small junction size of these TCs can provide more precise temperature readings. From the junction, the two TC wires then run in opposite directions. All the negative wires (Nickel-Aluminum) go downward and penetrate the porous plate. Small pieces of ceramic tube are used to insulate

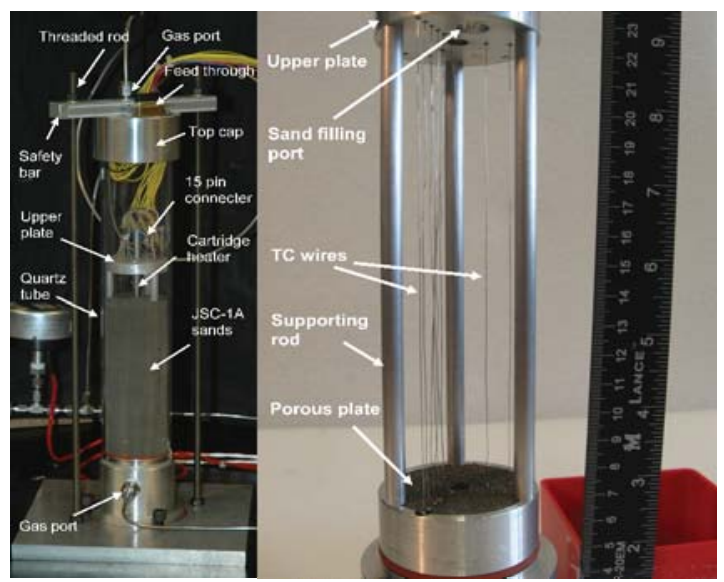

Figure 2. Photos of the test cell. The left photo shows the external view of the entire test cell and right photo shows the exposed thermocouple wires and the support frame. them from the plate before they connect to the electrical feed-through. All positive wires (NickelChromium) go upward and penetrate the top plate through small ceramic tubes. These wires then join the 4 wires from the heater (two for an imbedded Type $\mathrm{K}$ TC in the heater and two for the heater power) and terminate in a 15 pin connector, mounted on the upper plate. Near the top of each positive wire there is a tension section, acting as a spring to increase the stiffness of the wire so that the spatial position of the $\mathrm{TC}$ junction becomes more stable.

Figure 3 shows the orientation of the thermocouple junctions. To facilitate verification of the onedimensionality of the temperature field, the TC junctions were placed in different locations in a 3-D space; axial, radial, and azimuthal. Five thermocouples, TC1, TC3, TC5, TC6 and the TC in the heater are placed along the same radial line. These five TCs are considered as "baseline thermocouples" because their temperature readings only differ by radial location (see Fig. 3). The other six TCs are placed either at different azimuth or axial locations from the baseline thermocouples. The readings from these thermocouples can be compared with the baseline ones to provide an assessment of the one-dimensional temperature field assumption. Table A1 in the Appendix listed the coordinates of each TC junction.

Because the two thermocouple wires run in opposite directions (forming a closed loop with the data logging device), there was concern that the TC signal would be susceptible to stray electromagnetic interference. However, test results proved that these loops did not pick up any noticeable interference. This is likely owing to the very low impedance of TC junctions. 
Along the center line of the test section is a custom-designed Watlow cartridge heater, model WAT-EGA- 12515. It is rated at 400 watts with a $240 \mathrm{~V}$ input, and has an imbedded Type $\mathrm{K}$ thermocouple in the middle of the heated length. The diameter of the cartridge heater is $6.35 \mathrm{~mm}$ and the total length is $152.4 \mathrm{~mm}$, with a $127 \mathrm{~mm}$ heated length starting at $6.35 \mathrm{~mm}$ from the bottom end. By measuring the voltage and current at the heater, the total power supplied to the heater can be calculated accurately. This can then be used to determine the heat flux at the heater surface, which is needed to calculate thermal conductivity. Since the power and the heater dimensions are known, the question becomes how uniformly the heat flow is distributed over the heater length. According to the manufacturer, the heating wire is evenly coiled inside the heater. Thus, the heat generated per unit length should be uniform if the resistivity of the heating wire is constant. However, resistivity is a function of temperature and the temperatures are lower at both ends of the heater because of the end-effects. The extent of this nonuniformity can be assessed based on the thermal coefficient of the resistivity of the heating wire. In this case, the wire is made of nickel-chromium alloy with a thermal coefficient of resistivity to be $0.00015 /{ }^{\circ} \mathrm{C}$. Therefore, even if the temperatures at the two ends were lower by as much as $50^{\circ} \mathrm{C}$, the variation in the heat flux would be negligible. This justifies the uniform heat flux

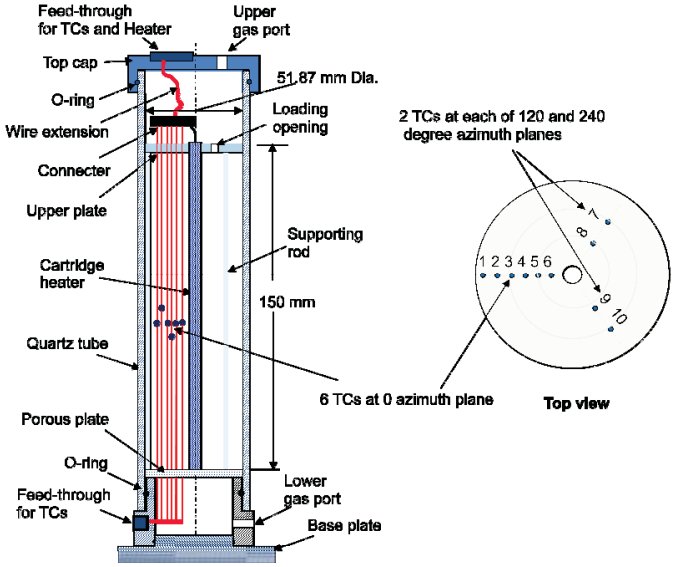

Figure 3. A schematic of the test cell showing the locations of thermocouples and the supporting structure. assumption so that the heat flux can be obtained by dividing the total wattage fed to the heater by the surface area of the heated section of the heater.

The top of the test cell is an aluminum cap that fits over the quartz tube. An o-ring in the cap's inner diameter seals against the outer diameter of the quartz tube. On the top surface of the cap, there is a threaded gas port and an electrical feed-through for the thermocouple wires and the heater power wires. This cap, along with a longer quartz tube, is a modification from the original design ${ }^{5}$ to permit subatmospheric pressure test conditions. A $10 \mathrm{~cm}$ long wire extension connects the feed through on the cap to the original connector on the top plate (Fig. 3). Thus, when this extension is disconnected, the top cap can be completely separated from the rest of the test cell. This makes it easier to load the simulant and permits the removal of the quartz tube. As shown in the left photo of Fig. 2, there is a safety bar installed above the top cap, connected to the base plate through two threaded rods on each side of the test cell. This is to secure the top cap in the event of an accidental positive pressure inside the test cell.

It should be noted that there are two gas ports on the test cell to allow flow through the sand bed in either direction. When tests without flowing gases are performed, the two ports are connected together to ensure the gas pressures above and below the sand bed are always the same. Therefore, the sand bed will not be disturbed when the gas pressure is adjusted. If gas pressure is adjusted through one port with the other one plugged, there will be a dead end in the test cell. The volume of this dead end will create a transient gas flow through the sand bed during pressure adjustment. It was observed that the sand bed was lifted because of this transient flow even though the rate of pressure change was very low. Thus, connecting both ports together is proven to be a good practice that eases the operation.

\section{B. Supporting Devices}

Figure 1 illustrates the schematic of the entire setup, including the test cell and the peripherals. Two Tektronix PS280 DC power supply units with adjustable output voltage were used to provide electric power to the heater, the pressure transducer and the data logging boards. Signals from the eleven thermocouples, the pressure transducer, and the heater voltage and current are all logged via a 16 channel multiplexer and a DAQ board that is controlled by a laptop computer. To improve the signal-noise ratio for thermocouple signals, the gain of the built-in pre-amplifier of the 16 channel multiplexer was set at x100 as recommended by the manufacturer, prior to the calibration of the data logging system. The user interface is a LabView program, which displays and logs data at $1 \mathrm{~Hz}$. While this manuscript only addresses ambient pressure tests, a gas system is in place for low pressure runs. This gas system includes a vacuum pump, a 57 liter buffer tank and a pressure transducer. The function of the buffer tank is to stabilize the pressure in the test cell during the four to five hour test runs. Without this tank, a slow leak may significantly affect the pressure in the test cell. 


\section{Preparation of the Tests}

Prior to conducting actual tests, the JSC-1A simulant sand was loaded, all the data logging devices were calibrated and a LabView program to control the experiment was written. After the quartz tube was set in place and before the top cap was installed, total 418 grams of the JSC-1A sand were loaded to the test cell through the sand filling port on the upper plate (see Fig. 2) with a long glass funnel. During the fill process, the quartz tube was gently tapped on the side to smooth sand settling and to prevent cavities from forming in the sand bed. After the sand was loaded, the height of the sand column in the test cell was $125 \mathrm{~mm}$. This gives a 5:1 ratio of height to radius of the sand column. This large aspect ratio is important in that the thermal end effects mentioned earlier can be minimized and a one-dimensional temperature distribution in the middle of the sand bed can be ensured. The bulk volume of the sand was estimated to be $248.18 \mathrm{~cm}^{3}$ by subtracting the volumes of the heater and the three supporting rods from the inner volume of the quartz tube. The corresponding bulk density of the sand is $1.684 \mathrm{~g} / \mathrm{cm}^{3}$. After the sand was loaded, the top cap was installed and all the electric connectors were connected.

Before testing began, the entire data logging system was calibrated and certified by the Calibration Laboratory at NASA John Glenn Research Center with NIST traceable standard devices. The LabView program was tested and debugged. The thermocouple positions were adjusted and recorded prior to installation of the quartz tube. A dummy run with a very low heater power was conducted to ensure the entire system functions properly.

\section{The Test Procedure}

After the simulant was loaded to the test cell and the data logging system was calibrated, a brief low temperature test was conducted to check the functionality of the system. Then a series of tests were performed, each with a fixed heat power input, i.e., a fixed voltage to the heater. To prevent potential damage to the thermocouples, these tests were run using the same soil. Each test began with powering up the data acquisition system and defining the log file. The LabView program was then engaged, the heater voltage was set to give the desired power. Once the heater was turned on, the test cell could not be disturbed, since this could impact the temperature gradients. The temperature history was monitored using the LabView window to make sure the heater temperature is below its maximum rated temperature $\left(760^{\circ} \mathrm{C}\right)$. When the temperature reached steady state (about $4.5 \sim 5$ hours), the heater was powered off. Temperature logging continued for a half hour to capture the cooling transient. The test was then terminated by ending LabView program and turning all the data logging devices off. The test cell was allowed to cool down to the room temperature completely before the next tests started.

\section{Results}

The ambient pressure test series began with low heater voltage (40 VDC). The heater voltage was increased by $10 \mathrm{~V}$ in each consecutive run until heater temperature approached its maximum allowable temperature. While data was logged for the entire test time, only the steady state portion was used in this study. This generally encompassed $\sim 100$ data points immediately prior to heater shutdown. These points were averaged to provide steady state temperature, heater power and pressure measurements. The results of six consecutive tests under the best controlled conditions are listed in Table A2 in the Appendix, including the average value and the standard deviation of each field. Gas pressures of these tests were controlled at $100 \mathrm{kPa}+/-1 \mathrm{kPa}$.

Figure 4 shows the temperature distributions in radial direction for all eleven thermocouples. The dots indicate the measured data. Because the radial distance of TC8 is only $0.03 \mathrm{~mm}$ greater than that of TC5 and their temperature readings are very close, the two data points merged in Fig. 4, resulting in only ten separated data points for each test. The fact that these two thermocouples are located in two different azimuth planes but have very close temperature readings is an indicator that the temperature field is axisymmetric.

The solid lines in Fig. 4 are the plots of the modeling functions obtained from least-squares regression analysis. The temperature distribution of each test can be well modeled by a logarithmic function.

$$
T(r)=A \ln r+B
$$

The resulting coefficients, $A$ and $B$, and the coefficient of determination, $R^{2}$, are listed in Table 1 . The coefficient of determination is a measure of the "goodness" of the modeling equation, with 1 being a perfect model. It can be seen that the values of all $R^{2} \mathrm{~s}$ are very close to one, indicating that the modeling function is a good representation of the data. Also listed in Table 1 are the derived apparent thermal conductivity (Eqn. 1) and the average temperature of each test calculated using coefficients $A$ and $B$. Note that the apparent thermal conductivity monotonically increases from Test 1 to Test 6. 
Table 1. The coefficients in Eq. (2), derived apparent thermal conductivities, and average temperatures for all six tests. Calculations used all 11 thermocouples.

\begin{tabular}{|c|c|c|c|c|c|c|}
\hline $\begin{array}{c}\text { Test } \\
\#\end{array}$ & $\begin{array}{c}\text { Heater } \\
\text { Power, W }\end{array}$ & $\mathrm{A},{ }^{\circ} \mathrm{C}$ & $\mathrm{B},{ }^{\circ} \mathrm{C}$ & $\mathrm{R}^{2}$ & $\mathrm{k}_{\mathrm{a}}, \mathrm{W} / \mathrm{m} /{ }^{\circ} \mathrm{C}$ & $\mathrm{T}_{\mathrm{a}},{ }^{\circ} \mathrm{C}$ \\
\hline 1 & 10.93 & -62.78 & 237.6 & 0.9989 & 0.2183 & 62.65 \\
2 & 16.55 & -91.39 & 339.3 & 0.9987 & 0.2270 & 84.58 \\
3 & 26.00 & -132.9 & 487.8 & 0.9992 & 0.2451 & 117.4 \\
4 & 32.28 & -158.0 & 578.2 & 0.9992 & 0.2560 & 137.9 \\
5 & 41.65 & -192.6 & 704.3 & 0.9993 & 0.2710 & 167.5 \\
6 & 53.67 & -233.7 & 855.4 & 0.9991 & 0.2878 & 204.1 \\
\hline
\end{tabular}

In order to verify the one-dimensionality of the temperature field, the same calculations were performed for the baseline thermocouple array only; TC1, TC3, TC5, TC6, and the heater TC. The model parameters $(A, B)$ are listed in Table A3 and were used to predict the temperatures at the non-baseline thermocouples. The difference between the predicted and actual temperature is then normalized by the total temperature span of each test to yield a relative deviation of each non-baseline thermocouple. When calculating the temperature span of each test, the temperature reading of $\mathrm{TC} 1$ is used to approximate the temperature at the quartz tube. Equation (3) shows how the relative deviation was calculated.

$$
\delta_{i j}=\frac{T_{f j}\left(r_{i}\right)-T_{j}\left(r_{i}\right)}{T_{j}\left(r_{\text {heater }}\right)-T_{j}\left(r_{1}\right)}
$$

where $T_{f j}$ and $T_{j}$ are the predicted and measured temperatures of the $j$-th test, respectively. Subscript $i$ and $j$ refer to the $i$-th thermocouple and the $j$-th test, respectively. Table 2 lists the values of all $\delta_{i j}$ of those non-baseline TCs. The absolute values of all $\delta_{i j}$ are within $2 \%$, which suggests that the assumption of one-dimensional temperature field is consistent with the actual temperature readings.

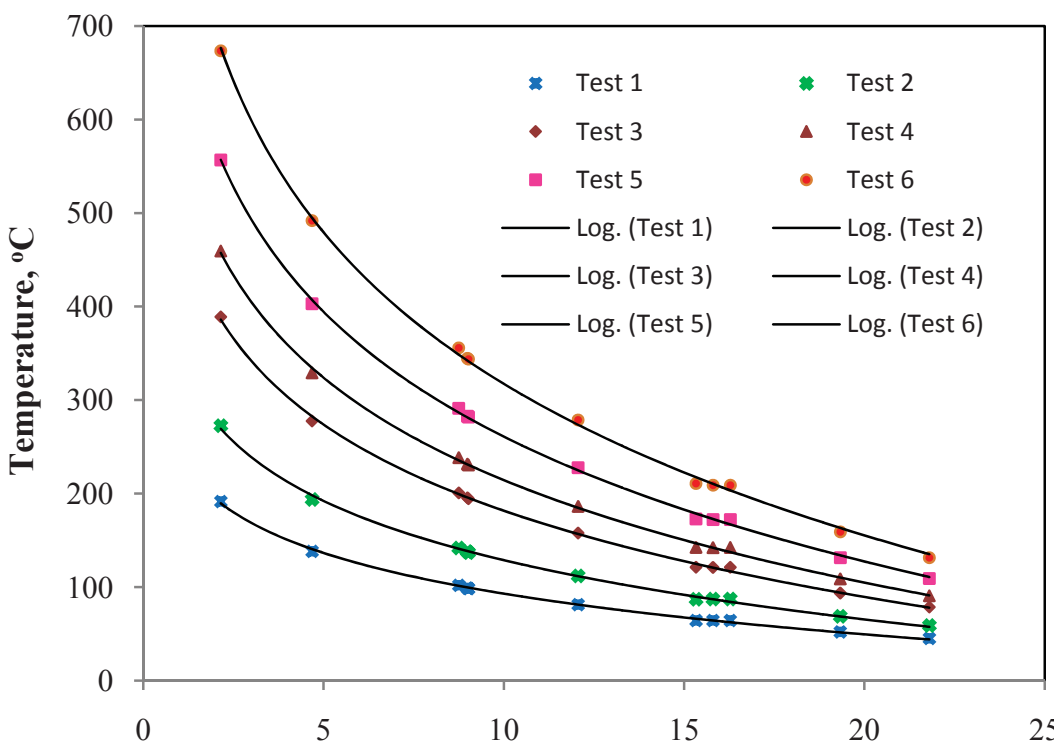

Radial Distance, mm

Figure 4. Temperature distribution of six tests with least squares regression plots. For all the tests, the temperature distribution can be modeled by a logarithm function with high accuracy, indicating a constant $k_{a}$ for each test. 
Table 2. Normalized temperature deviations of non-baseline TCs

\begin{tabular}{|c|c|c|c|c|c|c|}
\hline $\mathrm{r}, \mathrm{mm}$ & 12.06 & 19.33 & 9.02 & 16.28 & 8.75 & 15.8 \\
\hline Test \# & TC4 & TC2 & TC8 & TC7 & TC9 & TC10 \\
\hline 1 & -0.003 & -0.008 & 0.004 & -0.017 & -0.006 & -0.0052 \\
\hline 2 & -0.006 & -0.007 & 0.002 & -0.019 & -0.007 & -0.0068 \\
\hline 3 & -0.008 & -0.005 & -0.001 & -0.020 & -0.008 & -0.0064 \\
\hline 4 & -0.010 & -0.003 & -0.005 & -0.020 & -0.013 & -0.0068 \\
\hline 5 & -0.012 & -0.001 & -0.007 & -0.017 & -0.015 & -0.0047 \\
\hline 6 & -0.015 & 0.001 & -0.010 & -0.016 & -0.019 & -0.0036 \\
\hline
\end{tabular}

\section{Discussion}

\section{A. The Value of $\boldsymbol{k}_{a}$}

Based on the principle of conservation of energy and Eq. (1), the steady state heat transfer in the test cell can be modeled as follows.

$$
Q=-2 \pi r l k_{a} \frac{d T}{d r}
$$

where $Q$ is the total heat flow passing through the cylindrical surface with radius of $r$, and $l$ as the length of the heater. Substituting Eq. (2) into Eq. (4) yields

$$
k_{a}=-\frac{Q}{2 \pi l A} .
$$

In steady state, the total heat flow passing through all cylindrical surfaces concentric to the centerline of the test cell must be the same and equal to the electric power fed to the heater. Thus, $Q$ in Eq. (5) is a constant independent of $r$. Based on the values of $Q$ and the values of coefficient $A$ in Table 1, the corresponding apparent thermal conductivity of each test can be obtained. The calculated values of $k_{a}$ are listed in Table 1 . Because the values of $Q$ and coefficient $A$ are unique for each test, the value of $k_{a}$ must be constant for each test throughout entire volume of the test cell. Since the tests cover a wide temperature range, it can be concluded that the value of $k_{a}$ must be independent of temperature.

On the other hand, the value of $k_{a}$ varies between tests. In Table 1 it can be seen that the value of $k_{a}$ well correlates to, and monotonically increases with, the heater power of the tests. It changes from $0.217 \mathrm{w} / \mathrm{m} /{ }^{\circ} \mathrm{C}$ in Test \# 1 to $0.287 \mathrm{w} / \mathrm{m} /{ }^{\circ} \mathrm{C}$ in Test \# 6 ; a $24 \%$ increase between the two tests. But if $k_{a}$ is independent of temperature as discussed above, why does it vary between tests and increase with heater power? Interstitial radiation or convection effects cannot explain this phenomenon. Recalling that this is a conduction-only model (Eqn. 4), the presence of these effects would have shown a temperature dependent $k_{a}$. This is contrary to the observed logarithmic temperature distribution.

The variation of $k_{a}$ between tests may be attributed to different thermal stresses within the soil. The temperature of the outer quartz tube varies in a much narrower range than that of the inner sand bed. Figure 4 and Table A2 show that the temperature of TC1, which is nearest to the wall, changes $86^{\circ} \mathrm{C}$, whereas TC6, in the center of the sand bed, varies $\sim 350{ }^{\circ} \mathrm{C}$ across the six tests. The thermal expansion coefficient of fused quartz is $0.59 \mathrm{E}-6 /{ }^{\circ} \mathrm{C}$, such that over the $86^{\circ} \mathrm{C}$ temperature range, the expansion of the quartz tube is only $0.0102 \%$ in the inner cross-sectional area. Thus, it effectively forms a rigid boundary of the sand bed. When heated, the sand bed tends to expand and press against the quartz tube, creating a thermal stress within the bed. In an axisymmetric system, one of the principle stresses is in the radial direction, which is uniformly distributed in radial direction because there is no radial motion of the sand particles. Note that the free surface at the top of the sand bed cannot completely release the lateral stresses because in granular materials, forces distribute by following preferred path called "stress train" resulting in an anisotropic stress tensor. ${ }^{6}$ Thus, the stress in the radial direction is often different from that in the axial direction. More information about the stress-strain relations of granular materials can be found from Ref. 7-9. These stresses result in increased contact area between adjacent particles. Batchelor and O'Brien have shown that conduction through the 
solid phase dominates the conduction process in a granular medium when $a k_{s}>>r k_{f}$, where $k_{s}$ and $k_{f}$ are the conductivity of the solid and the fluid phase, respectively, and $a$ and $r$ are the radius of the contact spot and pores, respectively. ${ }^{10}$ Moreover, Molerus has noted that in the condition that $k_{s}>>k_{f}$, the contact conductance between adjacent particles is the controlling factor of heat conduction in static beds in the presence of a stagnant interstitial gas. ${ }^{11}$ Therefore, stress in a granular material can affect the thermal conduction process within it. In the current experiments, the fluid phase is air which has a thermal conductivity about two orders of magnitude lower than the solid phase. Thus the conclusion by Molerus applies here. When a steady state temperature distribution is reached, the lateral stress is uniform throughout the test bed for each test, but it is different from test to test because of different temperatures. The behavior of this stress well resembles that of the apparent thermal conductivity described above.

Because there is no direct measurement of stress in this experiment, it is not possible to directly correlate the apparent conductivity to the stress. The following calculations show that the thermal stress is a linear function of the average temperature of the sand bed. Thus an average bed temperature can be used as an indicator or quantifier of the stress. In material science, the thermal stress is calculated by equating the dilatation due to thermal expansion under the assumed stress-free condition to the contraction due to a compressing stress which is the thermal stress in this case. As temperature increases from $T_{0}$ to $T$, the volume change due to lateral thermal expansion of the sand bed can be calculated as follows.

$$
\Delta V=2 \pi l \beta \int_{r_{1}}^{r_{2}} r\left(T-T_{0}\right) d r
$$

where $T$ is the steady state temperature and $T_{0}$ the room temperature, $r_{l}$ and $r_{2}$ are the heater radius $(3.175 \mathrm{~mm})$ and the inner radius of the quartz tube $(25.93 \mathrm{~mm})$, respectively. Now, let us define a volumetric average temperature, $T_{a}$, in the following manner.

$$
T_{a}=\frac{\int T d V}{V_{0}}
$$

where $V_{0}$ is the total volume of the sand bed at the room temperature, $T_{0}$. By invoking Eq. (2) and carrying out the integral in Eq. (7), the average temperature of each test can be expressed in terms of coefficients $A$ and $B$ of the test as follows.

$$
T_{a}=2.787 A+B
$$

The calculated average temperatures for the six tests can be found in Table 1. On the other hand, substituting Eq. (7) into Eq. (6) gives the following expression of the would-be dilatation, i.e., the relative volume change because of the assumed thermal expansion.

$$
\frac{\Delta V}{V_{0}}=\beta\left(T_{a}-T_{0}\right)
$$

Equation (9) shows that the thermal dilatation is a linear function of the average temperature $T_{a}$. Since the thermal expansion coefficient $\beta$ is in the order of $1 \mathrm{E}-5 /{ }^{\circ} \mathrm{C}$ and the maximum value of $T_{a}$ is around $200^{\circ} \mathrm{C}$ of the six tests, the upper bound of the dilatation is estimated to be 0.002 , which is quite small in comparison with unity. Note that although this dilatation did not actually happen, its value is needed to calculate the thermal stress. Since the dilatation is small, it is reasonable to assume that the sand is under elastic deformation regime, which means a linear strain-stress relationship. In addition, any well-behaved non-linear function can be linearized in a small region. Therefore, we can further assume the following two linear relationships: 1) the apparent thermal conductivity is a linear function of the contact area between two adjacent particles, and 2) the contact area of two adjacent particles is a linear function of the stress in the sand bed. Therefore, relationship between the average temperature, $T_{a}$, and the apparent thermal conductivity, $k_{a}$, should be linear if the variation of the apparent thermal conductivity between the tests is truly caused by the thermal stress. To test this, the apparent thermal conductivity for each test is plotted against the average temperature in Fig. 5. The solid line is the plot of the modeling function resulting from a leastsquares regression, shown in Eq. (10) below.

$$
k_{a}=0.1861+0.0005 T_{a}
$$


The coefficient of determination, i.e., the $R^{2}$, of this linear model reaches 0.9986 , indicating a good fit. This supports the theory that the variation of $k_{a}$ between tests is very likely caused by thermal stress. It must be emphasized that Fig. 5 should not be construed as evidence that the thermal conductivity is a function of temperature. Here the average temperature, $T_{a}$, is only a measure or indicator of the thermal stress. Since there is no universally applied correlation between the average temperature and the thermal stress, Fig. 5 and Eq. (10) are only true for the existing apparatus; they cannot be generalized as a universally applied correlation.

To obtain the apparent thermal conductivity of the JSC-1A under a stress-free condition, a room temperature of $20^{\circ} \mathrm{C}$ is used in Eq. (10) to yield the value of stress-free apparent thermal conductivity of JSC-1A to be $0.1961 \mathrm{~W} / \mathrm{m} /{ }^{\circ} \mathrm{C}$. This value should be valid up to $650^{\circ} \mathrm{C}$, covered by the six tests.

\section{B. Uncertainty analysis}

A detailed uncertainty analysis of the experimental results was performed in accordance with procedures recommended by $\mathrm{NIST}^{12}$ and NPL ${ }^{13}$. Since the apparent thermal conductivity is not a directly measurable parameter, the uncertainty analysis included two steps. The first step was to evaluate the standard uncertainties of primary parameters that were directly measured from calibrated instruments, whereas the second step was to calculate the uncertainty propagation through the data reduction process to obtain the uncertainty of the final result. The second part was performed by following the law of propagation of uncertainty ${ }^{12}$. In this investigation, the primary parameters are the radial positions of the 11 thermocouples, the measured temperatures of the thermocouples, the measured electric power fed to the heater and the length of the heater. These primary parameters are needed in the data reduction

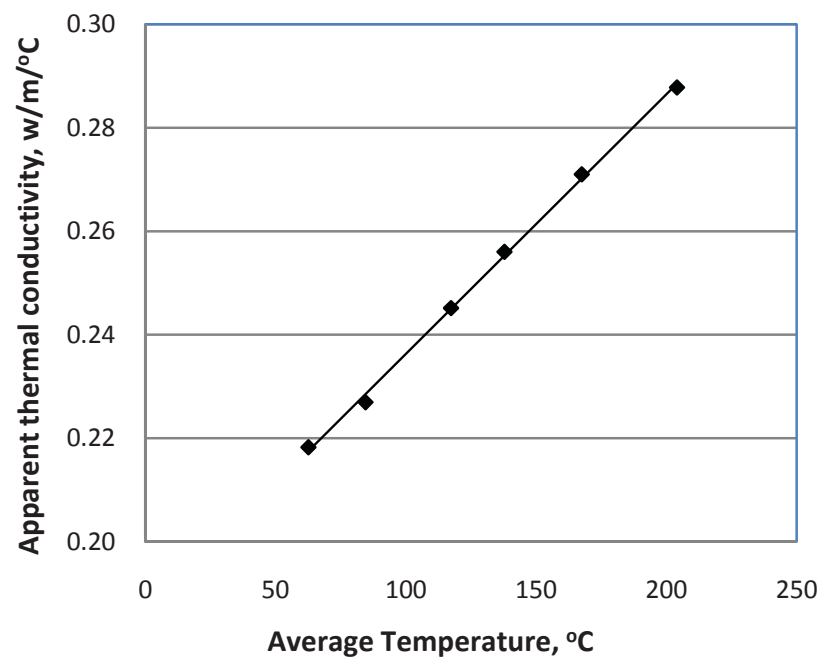

Figure 5. The apparent thermal conductivity appears to be a linear function of average temperature for the six tests, suggesting that thermal stress account for the different thermal conductivities between tests.

procedure to yield the final result. The uncertainties of these parameters include two types, Type A and Type B. Type A estimates are obtained from statistics, such as for repeated readings, whereas Type B estimates are from other sources such as calibration, etc. The combined standard uncertainty of each parameter equals to the square root of the sum of the squared value of each type of the two.

For the radial thermocouple positions, there is only a Type B uncertainty. The position of each thermocouple was measured from a high resolution image of the thermocouple junctions. In the image processing program, one pixel represents $0.305 \mathrm{~mm}$. The standard uncertainty of the radial distance of all the thermocouples is estimated to be $u\left(r_{i}\right)$ $=0.028 \mathrm{~mm}$. The temperature logging system was calibrated by the Calibration Laboratory at NASA GRC with NIST traceable apparatus. The best estimation of the Type B standard uncertainty of each thermocouple readings is $1^{\circ} \mathrm{C}$. The Type A standard uncertainties of temperature readings can be obtained by dividing the standard deviation of the 100 readings, listed in Table A2, by 10 (the square root of the number of readings, i.e., 100 in this case). ${ }^{12}$ From Table A2, we can see that the Type A standard uncertainties are much smaller than Type $\mathrm{B}\left(1^{\circ} \mathrm{C}\right)$, thus the combined standard uncertainties is very close to $1^{\circ} \mathrm{C}$. For the heat power measurement the standard uncertainties were mainly from Type A, because the Type B uncertainties (from calibration) of the voltage and current measurements are negligible in comparison. The standard uncertainty of the heater length is $1 \mathrm{~mm}$.

The uncertainty propagation analysis should be in parallel with the data reduction procedures. Thus, the first step of uncertainty propagation is to calculate the standard uncertainties of the two parameters $A$ and $B$ defined by Eq. (2) and listed in Table 1, based on the uncertainties of the temperature readings and the radial distances of each thermocouple. The sensitivity coefficient of $A$ and $B$ to the temperatures and radial distances can be derived from the functions of $A$ and $B$. The next step was to calculate the standard uncertainties of each $k_{a}$ and $T_{a}$ based on Eqs. (5) and (8) and the uncertainties of the heater power and heater length. Once the standard uncertainties of each $k_{a}$ and $T_{a}$ were obtained, the standard uncertainties of the two coefficients in Eq. (10) were calculated. The last step was to calculate the uncertainty into $k_{a}$ at $T_{a}=20^{\circ} \mathrm{C}$, based on the uncertainties of the two coefficients in Eq. (10). The 
uncertainty propagation calculation is quite straight forward because the equations relating various parameters are all known.

The apparent thermal conductivity of the JSC-1A under stress free condition is $k_{a}=(0.1961 \pm 0.0070) \mathrm{W} / \mathrm{m} /{ }^{\circ} \mathrm{C}$, where the number following the symbol \pm is the numerical value of an expanded uncertainty $U=k u_{c}$, with $U$ determined from a combined standard uncertainty $u_{c}\left(k_{a}\right)=0.0035 \mathrm{~W} / \mathrm{m} /{ }^{\circ} \mathrm{C}$ and a coverage factor $k=2$. Since it can be assumed that the possible estimated values of the standard are approximately normally distributed with approximate standard deviation $u_{c}$, the unknown values of the standard is believed to lie in the interval defined by $U$ with a level of confidence of approximately 95 percent. ${ }^{12}$

\section{Conclusion}

The thermal conductivity of JSC-1A was measured over a wide temperature range. The cylindrical apparatus created a 1-dimesional, axisymmetric temperature field, thus eliminating the need for lateral insulation so that very low thermal conductivity material could be measured. Unlike previous thermal conductivity studies of JSC-1A, multiple thermocouples were embedded in the soil bed to obtain a detailed radial temperature distribution. This steady state temperature distribution was modeled using a logarithmic function, which suggests that, in the temperature range covered by this investigation, the heat transfer in the sand bed is dominated by heat conduction; the contributions of interstitial radiation and natural convection are negligible. It also suggests that the apparent thermal conductivity is a constant throughout the entire sand bed for each test.

However, this thermal conductivity was not constant across the tests, which had different heater powers, and thus different steady state temperatures. This variation was attributed to thermal stresses within the soil bed. The rigid chamber wall of the apparatus resisted the thermal expansion in the granular soil material, thus building stress between the particles. Higher stresses increased contact between the particles, and thus provided a better heat conduction path. This indication that the apparent thermal conductivity is sensitive to the mechanical stress in the test material is consistent with previous studies. In an elastic regime, the apparent thermal conductivity appears to be a linear function of the stress, as shown in Eqn. (10), which defines conductivity as a function of average soil bed temperature. It is important to note that this equation is accurate only for this hardware configuration, i.e., this stress field. The stress-free thermal conductivity was calculated at $20^{\circ} \mathrm{C}$, where there is no thermal expansion effect. This stress-free thermal conductivity is $0.1961 \pm 0.0070 \mathrm{~W} / \mathrm{m} /{ }^{\circ} \mathrm{C}$, which is valid in the temperature range from room temperature up to $650^{\circ} \mathrm{C}$.

In ISRU applications, the regolith is heated within a rigid vessel. While the stress field would be dependent on the reactor dimensions, a stress-dependant thermal conductivity would apply for a stagnant soil bed. However, most reactors incorporate a fluidization, or mixing mechanism to speed heat transfer within the soil. In those applications, the apparent thermal conductivity is expected to be much enhanced by the flowing gases and the result obtained from stagnant soil bed may not apply.

\section{Appendix}

Table A1. Coordinates of all TC junctions measured form high resolution photos

\begin{tabular}{|c|c|c|c|c|c|c|c|c|c|c|c|}
\hline & Htr. TC & TC6 & TC5 & TC4 & TC3 & TC2 & TC1 & TC8 & TC7 & TC9 & TC10 \\
\hline $\mathrm{r}, \mathrm{mm}$ & $2.15 * *$ & 4.68 & 8.99 & 12.06 & 15.33 & 19.33 & 21.8 & 9.02 & 16.28 & 8.75 & 15.8 \\
\hline $\mathrm{h}, \mathrm{mm} *$ & $(63)^{* *}$ & 49.2 & 49.2 & 40.6 & 49.1 & 59.8 & 48.5 & 49.9 & 49.3 & 49 & 49.6 \\
\hline Azimuth, ${ }^{\circ}$ & 0 & 0 & 0 & 0 & 0 & 0 & 0 & 120 & 120 & 240 & 240 \\
\hline
\end{tabular}

*h is measured from the porous plate (see Fig. 3)

**The locations of the embedded TC in the heater are estimated. 
Table A2. Steady state temperature data and heater power for the six tests. Thermocouples are arranged by radial distance from the center of the test cell

\begin{tabular}{|c|c|c|c|c|c|c|c|c|c|c|c|c|c|}
\hline Test \# & & $\begin{array}{c}\text { Heater., } \\
{ }^{\circ} \mathrm{C}\end{array}$ & $\begin{array}{c}\mathrm{TC} 6, \\
{ }^{\circ} \mathrm{C}\end{array}$ & $\begin{array}{c}\mathrm{TC} 9, \\
{ }^{\circ} \mathrm{C}\end{array}$ & $\begin{array}{c}\mathrm{TC} 5, \\
{ }^{\circ} \mathrm{C}\end{array}$ & $\begin{array}{l}\mathrm{TC} 8, \\
{ }^{\circ} \mathrm{C}\end{array}$ & $\begin{array}{c}\mathrm{TC} 4, \\
{ }^{\circ} \mathrm{C}\end{array}$ & $\begin{array}{c}\mathrm{TC} 3, \\
{ }^{\circ} \mathrm{C}\end{array}$ & $\begin{array}{c}\text { TC10, } \\
{ }^{\circ} \mathrm{C}\end{array}$ & $\begin{array}{c}\mathrm{TC7}, \\
{ }^{\circ} \mathrm{C}\end{array}$ & $\begin{array}{c}\mathrm{TC} 2, \\
{ }^{\circ} \mathrm{C}\end{array}$ & $\begin{array}{c}\mathrm{TC} 1, \\
{ }^{\circ} \mathrm{C}\end{array}$ & $\begin{array}{c}\text { Heater. } \\
\text { Power, W }\end{array}$ \\
\hline \multirow{2}{*}{1} & Mean & 191.6 & 138.3 & 101.9 & 99.2 & 98.5 & 81.2 & 64.3 & 64.4 & 64.3 & 52.0 & 45.3 & 10.93 \\
\hline & Std. dev & 0.156 & 0.174 & 0.174 & 0.187 & 0.127 & 0.132 & 0.148 & 0.167 & 0.218 & 0.171 & 0.149 & 0.0032 \\
\hline \multirow{2}{*}{2} & Mean & 272.6 & 193.7 & 141.8 & 138.0 & 137.1 & 112.0 & 87.1 & 87.4 & 87.2 & 68.8 & 59.0 & 16.55 \\
\hline & Std. dev & 0.158 & 0.178 & 0.209 & 0.174 & 0.148 & 0.169 & 0.151 & 0.142 & 0.200 & 0.148 & 0.120 & 0.0035 \\
\hline \multirow{2}{*}{3} & Mean & 389.0 & 277.6 & 200.8 & 195.5 & 194.5 & 157.8 & 121.3 & 121.1 & 121.1 & 93.6 & 78.6 & 26.00 \\
\hline & Std.dev & 0.145 & 0.181 & 0.216 & 0.180 & 0.133 & 0.150 & 0.133 & 0.154 & 0.190 & 0.145 & 0.133 & 0.00432 \\
\hline \multirow{2}{*}{4} & Mean & 459.3 & 329.1 & 238.4 & 231.5 & 230.7 & 186.3 & 142.5 & 142.3 & 142.4 & 108.8 & 90.7 & 32.28 \\
\hline & Std. dev & 0.164 & 0.146 & 0.174 & 0.156 & 0.124 & 0.143 & 0.132 & 0.157 & 0.171 & 0.130 & 0.133 & 0.0062 \\
\hline \multirow{2}{*}{5} & Mean & 556.7 & 403.0 & 291.3 & 282.8 & 281.8 & 227.7 & 173.0 & 172.3 & 172.1 & 131.6 & 109.1 & 41.65 \\
\hline & Std. dev & 0.139 & 0.172 & 0.191 & 0.159 & 0.135 & 0.179 & 0.153 & 0.159 & 0.231 & 0.122 & 0.123 & 0.0061 \\
\hline \multirow{2}{*}{6} & Mean & 673.4 & 491.8 & 355.8 & 344.6 & 343.7 & 278.7 & 210.7 & 209.0 & 208.9 & 159.1 & 131.6 & 53.67 \\
\hline & Std. dev & 0.153 & 0.153 & 0.172 & 0.157 & 0.140 & 0.136 & 0.150 & 0.144 & 0.202 & 0.135 & 0.125 & 0.0075 \\
\hline
\end{tabular}

Table A3. Coefficients of modeling function based on five baseline thermocouple readings

\begin{tabular}{|c|c|c|c|}
\hline Test \# & $A$ & $B$ & $R^{2}$ \\
\hline 1 & -63.04 & 238.0 & 0.9991 \\
\hline 2 & -91.8 & 339.8 & 0.9989 \\
\hline 3 & -133.5 & 488.3 & 0.9994 \\
\hline 4 & -158.6 & 578.4 & 0.9996 \\
\hline 5 & -193 & 703.2 & 0.9997 \\
\hline 6 & -234.0 & 854.3 & 0.9996 \\
\hline
\end{tabular}

Note: Curve fit equation: $T(r)=A \ln (r)+B$

\section{Acknowledgments}

This work was supported by the In-Situ Resource Utilization Project. The majority of the apparatus was fabricated in 2009 under the Advanced Thermal Management Project. Both projects are part of the NASA Exploration Technology Development Program. The authors would like to also express their appreciation of the skilled efforts of Al Blaze and Donna Herbster in the fabrication and assembly of the apparatus.

\section{References}

${ }^{1}$ Bernett, E. C., Wood, H. L., Jaffe, L. D., and Martens, H. E., "Thermal properties of a simulated lunar material in air and vacuum," AIAA Journal, Vol. 1, No. 6, 1963, pp 1402-1407.

${ }^{2}$ Cremers, C. J., Birkebak, R. C., and Dawson, J. P., "Thermal conductivity of fines from Apollo 11," Proceedings of the APOLLO 11 Lunar Science Conference, Vol. 3, Houston, Texas, January 5-8, 1970, pp. 2045-2050.

${ }^{3}$ Cremers C. J., and Birkebak, R. C., "Thermal conductivity of fines from Apollo 12," Proceedings of the Second Lunar Science Conference, Vol. 3, The M.I.T. Press, 1971, pp. 2311-2315.

${ }^{4}$ Horai, K., Simmons, G., Kanamori, H., and Wones, D., "Thermal diffusivity, conductivity and thermal inertia of Apollo 11 lunar material," Proceedings of the APOLLO 11 Lunar Science Conference, Vol. 3, Houston, Texas, January 5-8, 1970, pp. 2243-2249.

${ }^{5}$ Yuan, Z.-G., Hasan, M. M., Kleinhenz, J. E., Hicks, M. C., Sacksteder, K. R., “An Experimental Investigation of the Apparent Thermal Conductivity of Lunar Regolith Simulant," AIAA-2010-6112, 40th International Conference on Environmental System, Barcelona, Spain, July 11-15, 2010

${ }^{6}$ Mindlin, R. D., "Compliance of Elastic Solids in Contact," Journal of Applied Mechanics, ASME x, 1949, pp.259-268.

${ }^{7}$ Deresiewicz, H., "Stress-strain Relations for a Simple Model of a Granular Medium," Journal of Applied Mechanics, Transactions ASME 25(3), 1958, pp. 402-406.

${ }^{8}$ Jenkins, J. T., "Volume Change in Small Strain Axisymmetric Deformations of a Granular Material," In Micromechanics of Granular Materials, Elsevier, Amsterdam, 1987, pp. 245-252. 
${ }^{9}$ Chan, H. S. and Liao, C. L., "Estimates of Elastic Modulus for Media of Randomly Packed Granules," Applied Mechanical Review 47, 1994, S197-S206.

${ }^{10}$ Batchelor, G. K., and O'Brien, R. W., "Thermal or Electrical Conduction Through a Granular Material," Proceedings of the Royal Society of London, 355, 1977, pp. 313-333.

${ }^{11}$ Molerus, O., "Heart Transfer in Moving Beds with a Stagnant Interstitial Gas," International Journal of Heat and Mass Transfer, 40, 1997, pp. 4151-4159.

${ }^{12}$ Taylor, B. N., Kuyatt, C. E., "Guidelines for Evaluating the Uncertainty of NIST Measurement Results," NIST Technical Note 1297, 1994 Edition.

${ }^{13}$ Bell, S.,"A Beginner's Guide to Uncertainty of Measurement," Issue 2, Measurement Good Practice Guide, The National Physical Laboratory, Teddington, Middlesex, United Kingdom, TW11 0LW, 1999. 